OPEN ACCESS

Edited by: Heike Wulff,

University of California, Davis, United States

Reviewed by: Nipavan Chiamvimonvat, University of California, Davis, United States Ricardo Gómez, University of La Laguna, Spain

*Correspondence: Bo Hjorth Bentzen bobe@sund.ku.dk

Specialty section: This article was submitted to Pharmacology of lon Channels and Channelopathies, a section of the journal Frontiers in Pharmacology

Received: 16 December 2019 Accepted: 20 April 2020

Published: 06 May 2020

Citation:

Bentzen BH, Bomholtz SH,

Simó-Vicens R, Folkersen L, Abildgaard L, Speerschneider T, Muthukumarasamy KM, Edvardsson N, Sørensen US, Grunnet M and Diness JG (2020)

Mechanisms of Action of the KCa2-Negative Modulator AP30663,

a Novel Compound in

Development for Treatment of Atrial Fibrillation in Man.

Front. Pharmacol. 11:610. doi: 10.3389/fphar.2020.00610

\section{Mechanisms of Action of the} KCa2-Negative Modulator AP30663, a Novel Compound in Development for Treatment of Atrial Fibrillation in Man

\author{
Bo Hjorth Bentzen ${ }^{1,2 *}$, Sofia Hammami Bomholtz ${ }^{1,2}$, Rafel Simó-Vicens ${ }^{1,2}$, \\ Lasse Folkersen $^{3}$, Lea Abildgaard ${ }^{1}$, Tobias Speerschneider ${ }^{1,2}$, \\ Kalai Mangai Muthukumarasamy ${ }^{2}$, Nils Edvardsson ${ }^{1,4}$, Ulrik S. Sørensen ${ }^{1}$, Morten Grunnet ${ }^{1}$ \\ and Jonas Goldin Diness ${ }^{1}$

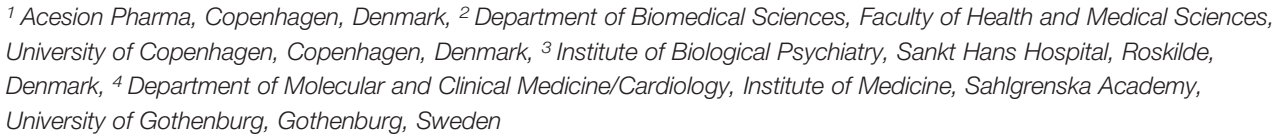
University of Copenhagen, Copenhagen, Denmark, ${ }^{3}$ Institute of Biological Psychiatry, Sankt Hans Hospital, Roskilde, Denmark, ${ }^{4}$ Department of Molecular and Clinical Medicine/Cardiology, Institute of Medicine, Sahlgrenska Academy, University of Gothenburg, Gothenburg, Sweden

Aims: Small conductance $\mathrm{Ca}^{2+}$-activated $\mathrm{K}^{+}$channels (SK channels, $\mathrm{K}_{\mathrm{Ca}}$ ) are a new target for treatment of atrial fibrillation (AF). AP30663 is a small molecule inhibitor of $\mathrm{K}_{\mathrm{Ca}} 2$ channels that is currently in clinical development for treatment of AF. The aim of this study is to present the electrophysiological profile and mechanism of action of AP30663 and its efficacy in prolonging atrial refractoriness in rodents, and by bioinformatic analysis investigate if genetic variants in KCNN2 or KCNN3 influence the expression level of these in human heart tissue.

Methods and Results: Whole-cell and inside-out patch-clamp recordings of heterologously expressed $\mathrm{K}_{\mathrm{C}_{2}} 2$ channels revealed that AP30663 inhibits $\mathrm{K}_{\mathrm{C}_{2}} 2$ channels with minor effects on other relevant cardiac ion channels. AP30663 modulates the $\mathrm{K}_{\mathrm{Ca}} 2.3$ channel by right-shifting the $\mathrm{Ca}^{2+}$-activation curve. In isolated guinea pig hearts AP30663 significantly prolonged the atrial effective refractory period (AERP) with minor effects on the QT-interval corrected for heart rate. Similarly, in anaesthetized rats 5 and $10 \mathrm{mg} / \mathrm{kg}$ of AP30663 changed the AERP to $130.7 \pm 5.4 \%$ and $189.9 \pm 18.6$ of baseline values. The expression quantitative trait loci analyses revealed that the genome wide association studies for AF SNP rs13376333 in KCNN3 is associated with increased mRNA expression of KCNN3 in human atrial appendage tissue.

Conclusions: AP30663 is a novel negative allosteric modulator of $\mathrm{K}_{\mathrm{Ca}} 2$ channels that concentration-dependently prolonged rodent atrial refractoriness with minor effects on the QT-interval. Moreover, AF associated SNPs in KCNN3 influence KCNN3 mRNA expression in human atrial tissue. These properties support continued development of AP30663 for treatment of AF in man.

Keywords: atrial fibrillation, ion channels, anti-arrhythmic drugs, $\mathrm{SK}$ channels, $\mathrm{K}_{\mathrm{Ca}} 2$ 


\section{INTRODUCTION}

Atrial fibrillation (AF) is the most common cardiac arrhythmia affecting more than 30 million people worldwide, a number that is rising partly because of the aging population and better detection. AF is associated with 2- and 1.5 fold increases in risk of all-cause mortality in woman and men respectively, and an increased risk of heart failure and stroke (Kirchhof et al., 2016). Management of patients with AF has improved, but pharmacological rhythm control therapy is still limited by moderately effective drugs with potentially serious extracardiac or ventricular adverse effects (Waks and Zimetbaum, 2016). Hence, novel pharmacological rhythm control therapies are warranted.

The small conductance calcium activated potassium channel (SK, $\mathrm{K}_{\mathrm{Ca}} 2$ ), encoded by the KCNNX gene is a new drug target for treatment of AF (Heijman and Dobrev, 2017). As the name implies, $\mathrm{K}_{\mathrm{Ca}} 2$ channels are potassium channels activated by intracellular calcium. Three subtypes of $\mathrm{K}_{\mathrm{Ca}} 2$ channel alfasubunits exists $\left(\mathrm{K}_{\mathrm{Ca}} 2.1-3, \mathrm{SK} 1-3\right)$ and in the human atria $\mathrm{K}_{\mathrm{Ca}} 2.2$ and $\mathrm{K}_{\mathrm{Ca}} 2.3$ predominate (Skibsbye et al., 2014). Genome wide association studies (GWAS) for AF have identified single nucleotide polymorphisms (SNPs) in KCNN2 and $K C N N 3$ that are highly associated with AF (Ellinor et al., 2010; Ellinor et al., 2012; Christophersen et al., 2017). Preclinical studies showed that $\mathrm{K}_{\mathrm{Ca}} 2$ channels during sinus rhythm as well as during AF play a more prominent role in atria as compared to ventricles in several species including man (Tuteja et al., 2005; Li et al., 2009; Diness et al., 2010; Qi et al., 2014; Skibsbye et al., 2014; Haugaard et al., 2015; Diness et al., 2017), thereby exhibiting a functional atrial specificity. In atrially tachy-paced pigs that were resistant to pharmacological cardioversion of $\mathrm{AF}$ with vernakalant, negative allosteric modulation of the $\mathrm{K}_{\mathrm{Ca}} 2$ channel converted AF to sinus rhythm (Diness et al., 2017). In the current study, we first investigate if genetic variants (SNPs) in KCNN2 or KCNN3 found in GWAS to be associated with AF influence the expression level of KCNN2 or KCNN3 in human atrial or ventricular tissue. Next, we present the ion channel profile, mode of action, and in vitro, ex vivo and in vivo effects of the clinical candidate AP30663.

\section{MATERIALS AND METHODS}

\section{Expression Quantitative Trait Loci Analyses}

The expression quantitative trait loci analyses (eQTL) effects of the AF GWAS associated SNP rs337711 on KCNN2 and SNP rs 13376333 on KCNN3 were investigated in the Genotype-Tissue Expression (GTEx) database, release v05-08-15, using default dashboard analytics setup. GTEx data gene expression was measured using RNA-sequencing with Illumina TruSeq library and genotyping was done using whole genome sequencing on an illumina HiSeq X machine (Carithers et al., 2015). For eQTL replication we used the Advanced Study of Aortic Pathology (ASAP) cohort of left-ventricular heart tissue, measured using
Affymetrix ST 1.0 Arrays and genotyping was done using Illumina Human 610W-Quad Beadarrays (Folkersen et al., 2011). The statistical calculation was performed using a linear additive model, where genotype was encoded as 0,1 , or 2 and used as explanatory variable, with gene expression level as response variable.

\section{In Vitro Electrophysiology}

The potency of AP30663 was assessed in HEK cells stably expressing rat $\mathrm{Na}_{\mathrm{V}} 1.5$ or human $\mathrm{Ca}_{\mathrm{V}} 1.2, \mathrm{~K}_{\mathrm{Ca}} 2.1, \mathrm{~K}_{\mathrm{Ca}} 2.2$ or $\mathrm{K}_{\mathrm{Ca}} 2.3$ channels and $\mathrm{CHO}$ cell line stably expressing human $\mathrm{K}_{\mathrm{V}} 11.1$ using the automated patch-clamp system, Qpatch 16 (Sophion, Ballerup, Denmark) at room temperature. The effect of AP30663 on heteromeric $K_{V} 11.1 \mathrm{a}$ and $K_{V} 11.1 b$ channels was addressed by manual patch clamping. Inside out patch-clamp recordings were performed on HEK cells stably expressing human $\mathrm{K}_{\mathrm{Ca}} 2.3$ channels using a HEKA EPC9 amplifier and the Patchmaster software (HEKA Elektronik, Germany). Effects of AP30663 on late $\mathrm{Na}_{\mathrm{V}} 1.5$ currents were addressed by manual whole-cell patch-clamping using HEK cells transiently transfected with human $\mathrm{Na}_{\mathrm{V}} 1.5$ in the absence and presence of ATXII. The effect of AP30663 was also assessed on the currents conducted by Kir2.1 $\left(\mathrm{I}_{\mathrm{K} 1}\right) ; \mathrm{K}_{\mathrm{V}} 7.1 / \mathrm{KCNE} 1\left(\mathrm{I}_{\mathrm{ks}}\right) ; \mathrm{K}_{\mathrm{V}} 4.3 / \mathrm{KCHIP} 2$ $\left(\mathrm{I}_{\mathrm{to}}\right), \mathrm{K}_{\mathrm{ir}} 3.1 / \mathrm{K}_{\mathrm{ir}} 3.4\left(\mathrm{I}_{\mathrm{KACh}}\right)$; and $\mathrm{K}_{\mathrm{V}} 1.5$ ( $\left.\mathrm{I}_{\mathrm{Kur}}\right)$ using the twoelectrode voltage-clamp method on Xenopus oocytes, as previously described (Diness et al.). See details of in vitro electrophysiology methods in Supplementary Methods and Materials.

\section{Animal Experiments}

Animal experiments were performed under the license from the Danish Ministry of justice (2018-15-0201-01430 \& 2016-150201-00850) and in accordance with the Danish guidelines for animal experiments according to the European Commission Directive 86/609/EEC.

\section{Isolated Perfused Guinea Pig Heart Experiments}

A total of 12 female and 6 male Guinea pig hearts were used. In brief after anesthesia the hearts were removed and retrogradely perfused with Krebs-Henseleit solution via the aorta. Hearts were mounted in a Langendorff set-up (Hugo Sachs Elektronik, Germany) and electrocardiograms (ECG) were obtained with three ECG electrodes placed near the heart. A pacing electrode on the right atrium was used to stimulate the atria and measure atrial refractory periods (AERP).

After the baseline recording, three 20-min episodes followed in which the heart was perfused with increasing concentrations of AP30663 $(1,3$, and $10 \mu \mathrm{M})$. Time matched control hearts underwent the same procedure. For details see Supplementary Methods.

\section{Irwin}

An observational Irwin test for assessing CNS exposure of AP30663 was performed in mice. A total of three NMRI mice (Taconic Europe, Lille Skensved, Denmark) weighing 40 to $60 \mathrm{~g}$ were used. After injection of a bolus dose of $10 \mathrm{mg} / \mathrm{kg} \mathrm{AP30663}$ in the tail vein, the mice were observed for up to $30 \mathrm{~min}$. 


\section{Closed Chest Rat AERP}

A total of seven male Sprague-Dawley rats were used for the closed chest preparations. The rats were anaesthetized with $3 \%$ isofluran/oxygen and catheterized to allow for drug infusion and intra cardiac pacing. The AERP was measured by applying electrical stimulation. Baseline AERP recordings were made every fifth minute for $20 \mathrm{~min}$. Hereafter, two 20-min episodes followed in which the animal was injected with increasing doses of AP30663 (5 and $10 \mathrm{mg} / \mathrm{kg}$ ) or equivalent volumes of vehicle. AERP was measured $0.5,2,4,6,10$, and $15 \mathrm{~min}$ after each injection. For details see Supplementary Methods.

\section{Drugs and Solutions}

AP30663 was solubilized in DMSO stock concentrations of 10 $\mathrm{mM}$ for in vitro experiments. The highest concentration of DMSO was $0.1 \%$. For in vivo experiments, $5 \mathrm{mg} / \mathrm{ml} \mathrm{AP30663}$ were dissolved in a vehicle consisting of $50 \%$ polyethylene glycol (PEG) 400 (Merck, Germany) and 50\% sterile saline (PanReac AppliChem, Germany).

\section{Data Analysis}

In vitro data were extracted from PatchMaster or Sophion QPatch Assay Software and analyzed using GraphPad Prism 7. For detailed description, see Supplementary Methods. Data are summarized as mean \pm SEM.

In vivo and ex vivo experiments were analyzed using GraphPad Prism software. LabChart software was used for analyzing the following ECG parameters: QT, PR, RR, QRS. The QT-interval corrected for heart rate, QTcH, was calculated as described in Holzgrefe et al. (2014) using the guinea pig specific formula:

$$
\mathrm{QTcH}=\mathrm{QT} /(\mathrm{RR} / 0.28)^{0.7861} \text {. }
$$

Continuous data are summarized using the mean \pm SEM. Multiple unpaired t-tests without assuming consistent standard deviations and using Holm-Sidaks correction for multiple comparisons were used to compare the AP30663 groups to their respective TMC. $P$ values $<0.05$ were considered significant and are given with three decimals. Manuscript Formatting.

\section{RESULTS}

\section{AF-Associated SNPs in KCNN3 Influences KCNN3 mRNA Expression in Human Atrial Tissue}

We found that the minor allele T of SNP rs13376333 was associated with higher mRNA expression of KCNN3 in the GTEx atrial appendage samples (Figure 1) $(P=0.0223, \mathrm{n}=$ 264). In the one other GTEx heart-related tissue available, the left ventricle, there was also a trend towards increased expression with the minor allele $\mathrm{A}$, although not statistically significant $(P=$ $0.0818, n=272$ ). Additionally, we observed the same effect in the lung tissue $(P=2.13 \mathrm{e}-8)$ and in one brain region tissue (the BA24 region, $\mathrm{P}=0.0162$ ). The cardiac eQTL effect was replicated in independent samples of left ventricular biopsies from patients

\section{KCNN3 (ENSG00000143603.14) and rs13376333}

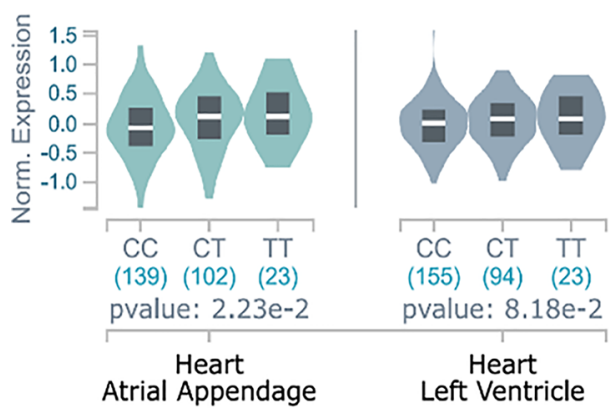

FIGURE 1 | eQTL effects of rs13376333 on KCNN3. Y-axis indicates normalized expression value of KCNN3 according to the GTEx standard analysis pipeline (Carithers et al., 2015). The figure shows that the expression of KCNN3 in atrial appendage is increased in the 23 GTEx individuals with the rs13376333-T/T genotype, as compared to both the 102 heterozygote (C/T) GTEx individuals and the 139 individuals that are major allele homozygote (C/C). Having the T-allele have also been shown to increase risk of AF (Ellinor et al., 2010; Ellinor et al., 2012; Christophersen et al., 2017). These findings were replicated in an independent eQTL data $(P=0.0162, \mathrm{n}=127)$.

undergoing surgery in the ASAP study, also with the minor allele $\mathrm{T}$ resulting in increased expression $(\mathrm{P}=0.0162, \mathrm{n}=127)$. In comparison SNP rs337711 was not associated with atrial or ventricular changes in KCCN2 mRNA expression $(P=0.6$ and $P=0.1$, respectively).

\section{AP30663 Inhibits $\mathrm{K}_{\mathrm{Ca}} 2$ Channels by Modifying the Calcium Sensitivity of the Channel}

AP30663 inhibited the $\mathrm{K}_{\mathrm{Ca}} 2$ current in a concentrationdependent manner (Figures 2A-C). The concentration response curves show that $\mathrm{AP} 30663$ inhibits all $\mathrm{K}_{\mathrm{Ca}} 2$ channel subtypes but with a slightly lower potency on $\mathrm{K}_{\mathrm{Ca}} 2.1 \quad\left(\mathrm{IC}_{50}=\right.$ $2.29 \pm 0.22 \mu \mathrm{M} ; \mathrm{K}_{\mathrm{Ca}} 2.2, \mathrm{IC}_{50}=1.46 \pm 0.28 \mu \mathrm{M} ; \mathrm{K}_{\mathrm{Ca}} 2.3, \mathrm{IC}_{50}=$ $1.09 \pm 0.09 \mu \mathrm{M})$ (see Figures 2D, E).

To investigate the inhibitory mechanism of AP30663, we performed inside out patch-clamp experiments on HEK cells expressing $\mathrm{K}_{\mathrm{Ca}} 2.3$ (Figure 3). In the absence of AP30663 the $\mathrm{K}_{\mathrm{Ca}} 2.3$ channel had an $\mathrm{EC}_{50}$ for calcium activation of $0.33 \pm$ $0.02 \mu \mathrm{M}$ and was fully active at $3 \mu \mathrm{M}$. However, in the presence of $7 \mu \mathrm{M}$ AP30663, $10 \mu \mathrm{M}$ of calcium is needed to achieve full activation, and the $\mathrm{EC}_{50}$ for calcium activation is shifted to $1.50 \pm$ $0.12 \mu \mathrm{M}\left(\mathrm{EC}_{50}\right.$ baseline vs. AP30663: $\left.P<0.0001\right)$. In addition to shifting the calcium activation curve, meaning that higher concentrations of calcium are needed to activate the channel, AP30663 also significantly decreased the Hill slope of the calcium activation curve from $4.4 \pm 0.5$ to $1.4 \pm 0.1$ (slope baseline vs. AP30663: $P<0.0001)$.

\section{Ion Channel Selectivity Profile of AP30663}

AP30663 was tested on a panel of cardiac ion channels to determine the functional selectivity profile of the compound. Automated whole-cell patch-clamp recordings of $\mathrm{hK}_{\mathrm{V}} 11.1 \mathrm{a}$ 


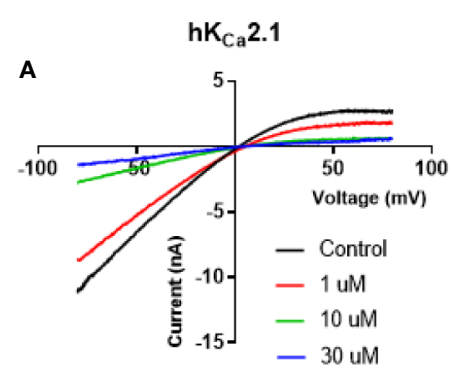

B

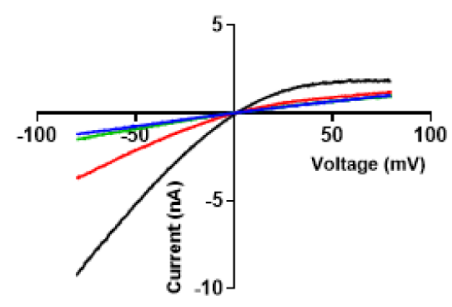

$\mathrm{hK}_{\mathrm{Ca}} 2.3$

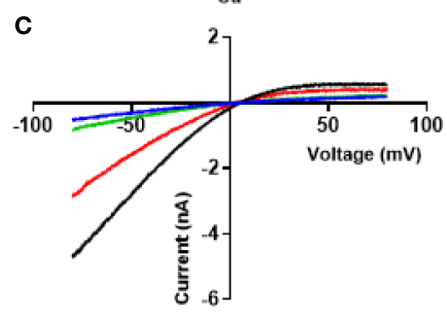

D

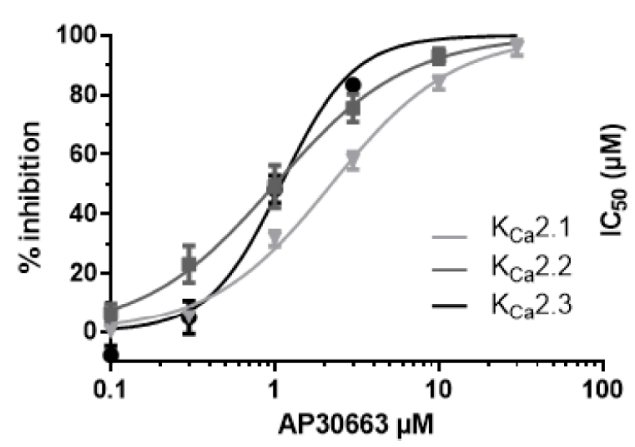

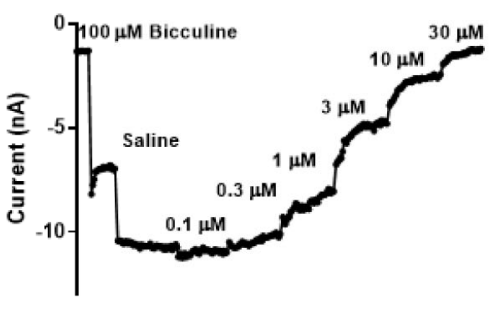
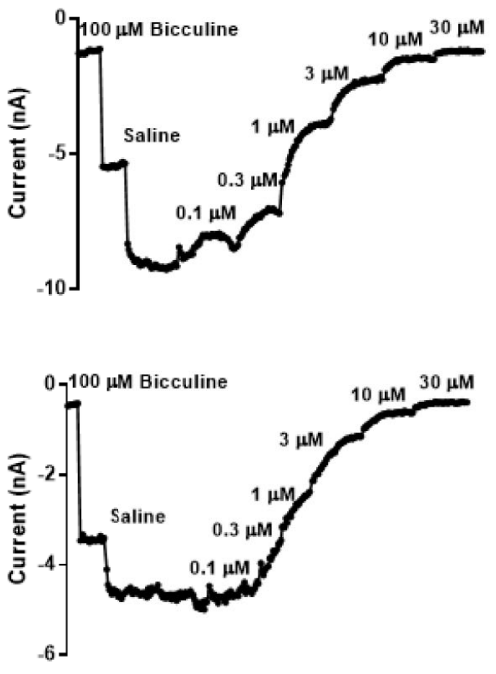

E

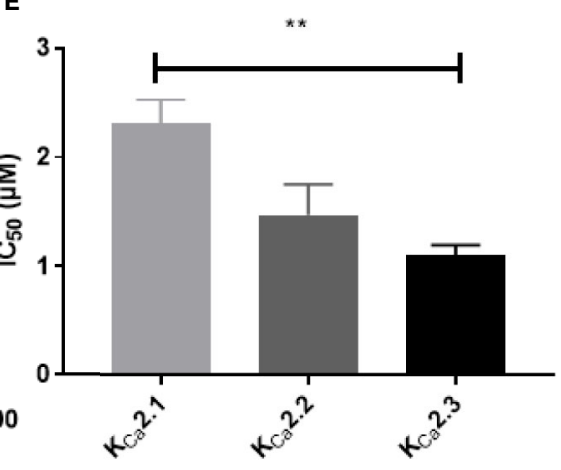

FIGURE 2 | AP30663 inhibits $\mathrm{hK}_{\mathrm{Ca}} 2$ channels. The effect of increasing concentrations of AP30663 was investigated by automated whole-cell patch-clamping in HEK cells stably expressing human $\mathrm{K}_{\mathrm{Ca}} 2$ channels. Currents were elicited by applying a depolarizing voltage ramp protocol from $-80 \mathrm{mV}$ to $+80 \mathrm{mV}$ for $200 \mathrm{~ms}$ from a holding potential of $0 \mathrm{mV}$ in symmetrical $\mathrm{K}^{+}$solutions. Current-voltage recordings are depicted in the left panel for $\mathrm{K}_{\mathrm{Ca}} 2.1$ (A), $\mathrm{K}_{\mathrm{Ca}} 2.2$ (B) and $\mathrm{K}_{\mathrm{Ca}} 2.3$ (C) before (black) and after application of $1 \mu \mathrm{M}$ (red), $10 \mu \mathrm{M}$ (green) and $30 \mu \mathrm{M}$ (blue) AP30663. Current-time plots (right panel) showing the effect of increasing concentrations of AP30663 on the for $\mathrm{K}_{\mathrm{Ca}} 2.1$ (A), $\mathrm{K}_{\mathrm{Ca}} 2.2$ (B), and $\mathrm{K}_{\mathrm{Ca}} 2.3$ (C) currents measured at a membrane potential of -80 mV. (D) Concentration-response curve of AP30663 on $\mathrm{K}_{\mathrm{Ca}} 2.1$ (light gray), $\mathrm{K}_{\mathrm{Ca}} 2.2$ (dark gray), and $\mathrm{K}_{\mathrm{Ca}} 2.3$ (black). (E) Comparison of $\mathrm{IC}_{50}$ values for the $3 \mathrm{~K}_{\mathrm{Ca}} 2$ channel subtypes. ( $\mathrm{K}_{\mathrm{Ca}} 2.1$, $\mathrm{n}=9$; $\mathrm{K}_{\mathrm{Ca}} 2.2, \mathrm{n}=$ 19; and $\left.\mathrm{K}_{\mathrm{Ca}} 2.3, \mathrm{n}=16\right)$. ${ }^{\star \star} \mathrm{p}<0.01$.

channels revealed that AP30663 inhibited the $\mathrm{I}_{\mathrm{Kr}}$ current with an $\mathrm{IC}_{50}$ value of $15.1 \pm 2.1 \mu \mathrm{M}$ (Figure $4 \mathrm{~A}$ ). In comparison when tested by manual patch clamp at $35^{\circ} \mathrm{C}$, on HEK cells transfected with both cardiac isoforms $\mathrm{K}_{\mathrm{V}} 11.1 \mathrm{a}$ and $\mathrm{K}_{\mathrm{V}} 11.1 \mathrm{~b}$, AP30663 was estimated to have an $\mathrm{IC}_{50}$ of $4.0 \pm 1.5 \mu \mathrm{M} .10 \mu \mathrm{M}$ AP30663 did not significantly affect $\mathrm{K}_{\mathrm{ir}} 3.1 / \mathrm{K}_{\mathrm{ir}} 3.4\left(\mathrm{I}_{\mathrm{KACh}}\right), \mathrm{K}_{\mathrm{V}} 1.5\left(\mathrm{I}_{\mathrm{Kur}}\right), \mathrm{K}_{\mathrm{V}} 7.1 /$
$\operatorname{KCNE} 1\left(\mathrm{I}_{\mathrm{Ks}}\right), \mathrm{K}_{\mathrm{V}} 4.3 / \mathrm{KChiP} 2\left(\mathrm{I}_{\mathrm{to}}\right)$ and $\mathrm{K}_{\mathrm{ir}} 2.1\left(\mathrm{I}_{\mathrm{K} 1}\right)$ channels Figure 4B). AP30663 did not significantly inhibit the current mediated by $\mathrm{Ca}_{\mathrm{V}} 1.2\left(\mathrm{I}_{\mathrm{Ca}}\right.$ ) (inhibition by $30 \mu \mathrm{M}: 4 \pm 7 \%$ ). The effects on peak $\mathrm{Na}_{\mathrm{V}} 1.5$ channel current $\left(\mathrm{I}_{\mathrm{Na}}\right)$ were investigated by automated patch-clamp experiments, and AP30663 in $10 \mu \mathrm{M}$ did not affect $\mathrm{I}_{\mathrm{Na}}(4 \pm 1 \%$ inhibition) (Figure 4B). 

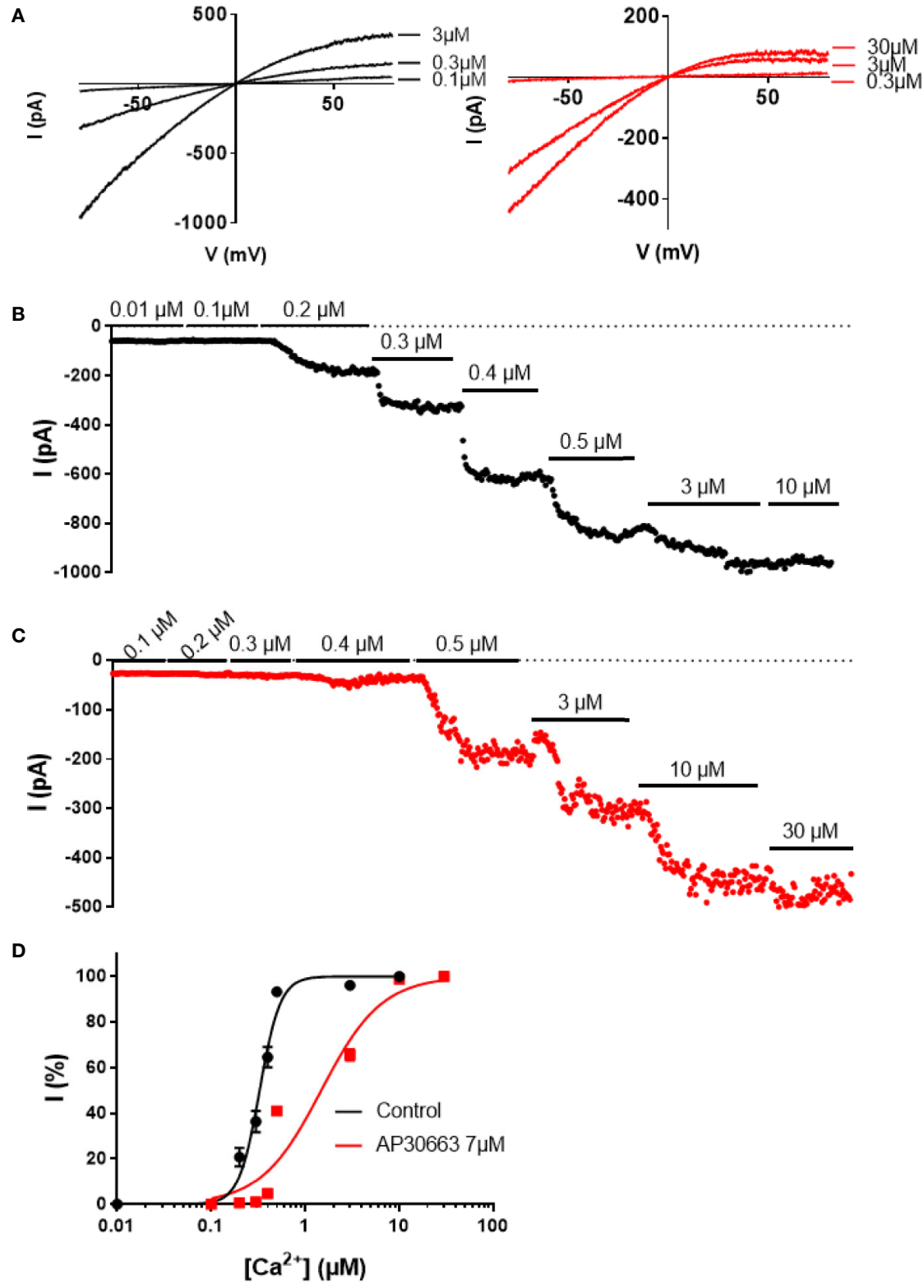

FIGURE 3 | AP30663 shifts the calcium activation curve of $\mathrm{hK}_{\mathrm{Ca}} 2.3$ channels. Current-voltage recordings (A) and corresponding current-time plots of $\mathrm{K}_{\mathrm{Ca}} 2.3$ measured using the inside-out patch-clamp exposed to different free calcium concentrations, in the absence (B) (black) or presence of AP30663 7 MM (C) (red). (D) Calcium activation curves for $\mathrm{K}_{\mathrm{Ca}} 2.3$ in the absence (black, $\mathrm{n}=6$ ) or presence of AP30663 $7 \mu \mathrm{M}(\mathrm{red}, \mathrm{n}=6)$. Currents were measured at a membrane potential of $-80 \mathrm{mV}$.

To determine if AP30663 had any effect on the late $I_{\mathrm{Na}}$, we conducted a set of manual patch-clamp experiments on HEK cells transfected with the human $\mathrm{Na}_{\mathrm{V}} 1.5$ channel. Because of its small size, it is customary to co-apply the sea anemone toxin ATXII to augment late $\mathrm{I}_{\mathrm{Na}}$, and to use the sodium channel toxin tetrodotoxin (TTX) at the end of the experiment to inhibit residual late $\mathrm{I}_{\mathrm{Na}}$ (Isenberg and Ravens, 1984; Maltsev et al., 1998). In Figure 4C, it can be seen how ATXII slows the inactivation of $\mathrm{Na}_{\mathrm{V}} 1.5$ and causes a small but relevant increase of the late current. From the time plot in Figure 4D, it can be appreciated that ATXII in our hands causes a continuous increase in the late $\mathrm{I}_{\mathrm{Na}}$ amplitude. Hence, a steady state current is never achieved, and therefore judging the effect of AP30663 solely based on changes in late $\mathrm{I}_{\mathrm{Na}}$ amplitude would be difficult. To circumvent this, we quantified the effect of $10 \mu \mathrm{M}$ AP30663 on ATXII augmented late $\mathrm{I}_{\mathrm{Na}}$ by comparing the changes in the slope of the late $\mathrm{I}_{\mathrm{Na}}$ vs time plot. From the bar graph that summarizes the effect of AP30663 on the slope from 14 


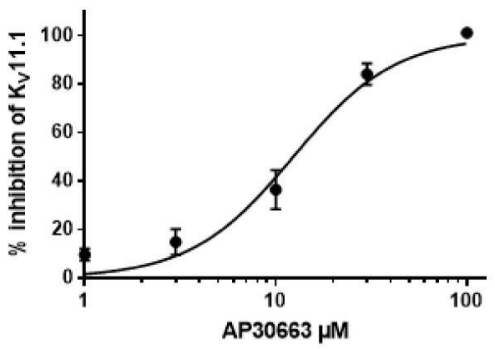

B

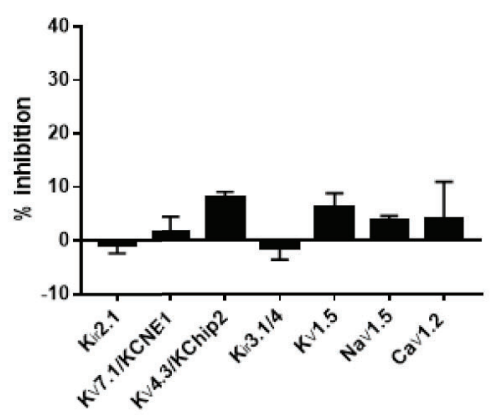

C

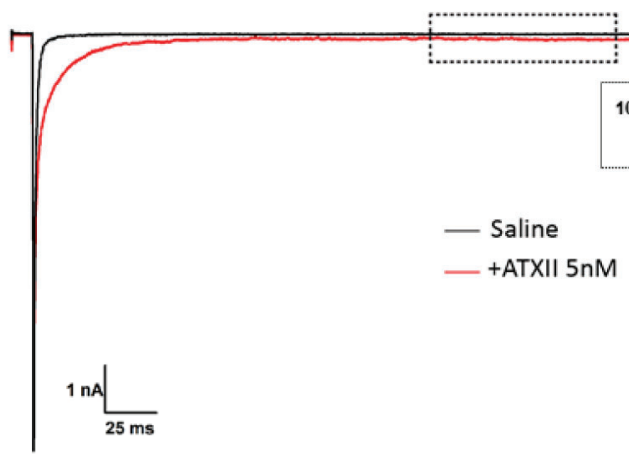

D

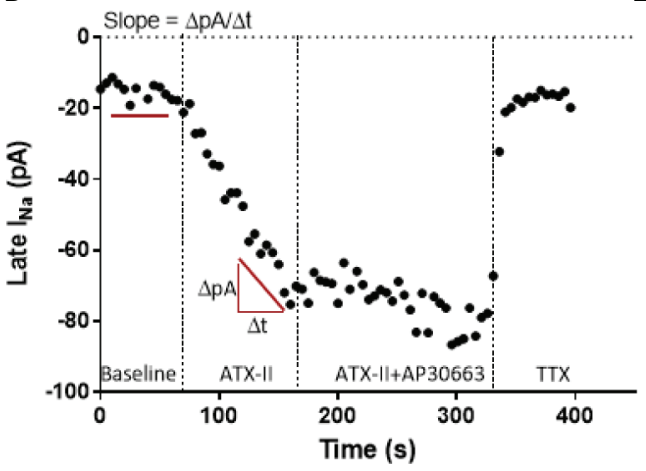

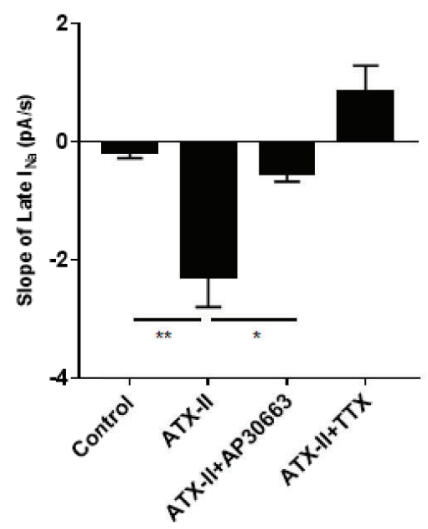

FIGURE 4 | lon channel selectivity profile of AP30663. (A) Concentration-response curve of the effect of increasing concentrations of AP30663 on $K_{V} 11.1 \mathrm{a}$ recorded by automated whole-cell patch-clamp $(n=4)$. (B) \% inhibition by $10 \mu \mathrm{M}$ AP30663 on $\mathrm{K}_{\mathrm{ir}} 3.1 / \mathrm{K}_{\mathrm{i}} 3.4\left(\mathrm{I}_{\mathrm{KACh}}, \mathrm{n}=6\right), \mathrm{K}_{\mathrm{v}} 1.5\left(\mathrm{I}_{\mathrm{Kur}}, \mathrm{n}=5\right), \mathrm{K}_{\mathrm{v}} 7.1 / \mathrm{KCNE} 1\left(\mathrm{I}_{\mathrm{Ks}}, \mathrm{n}=\right.$ 5), $K_{v} 4.3 / K C h i P 2\left(I_{t o}, n=5\right)$, and $K_{i r} 2.1\left(I_{K 1}, n=5\right)$ using two-electrode voltage-clamp and Nav1.5 ( $\left.I_{N a}, n=11\right)$, Cav $1.2\left(l_{C a}, n=3 ; 30 \mu M\right)$ using automated wholecell patch-clamping. (C) Current traces of the whole-cell $\mathrm{Na}^{+}$current before and after application of ATXII recorded from HEK293 cells transiently transfected with hNav1.5 (dotted box demonstrates where the late-sodium current was analyzed). (D) Late-sodium current amplitudes as a function of time. (E) Effect of compounds on the slope of the late-sodium current vs time plot. The slope was found by linear regression on the last 10 points of each liquid period $(n=14)$.

experiments it can be concluded that $10 \mu \mathrm{M}$ AP30663 inhibits the late $\mathrm{I}_{\mathrm{Na}}$ (Figure 4E).

\section{AP30663 Prolongs the Atrial Refractory Period With Small Effects on Ventricular Repolarization-Functional Atrial Selectivity}

A well-known anti-arrhythmic mechanism of rhythm control therapeutics is to prolong atrial refractoriness. After a baseline period the effects of increasing concentrations of AP30663 (1, 3 , and $10 \mu \mathrm{M}$ ) on AERP in isolated female guinea pig hearts were investigated. From Figure 5, it can be appreciated that AP30663 increases AERP in a concentration-dependent manner, while QTcH is prolonged to a much lesser degree. To take into account baseline differences we evaluated the effect of AP30663 by comparing $\Delta$ drug-baseline between TMC and AP30663 groups for each concentration (Table 1). From this it can be observed that AP30663 significantly prolongs AERP at all concentrations, slows the heart rate in 3 and 10 $\mu \mathrm{M}$, prolongs the QRS in $10 \mu \mathrm{M}$ and prolongs the PQ-interval and QTcH-interval. The latter albeit to a much lesser extent 


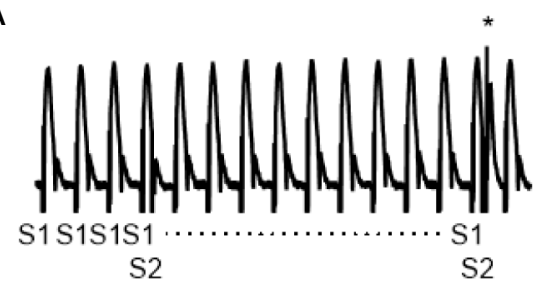

C
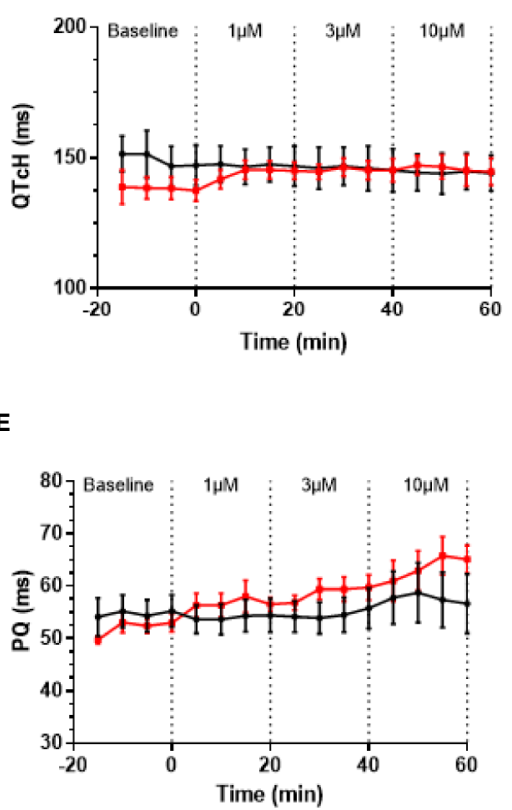

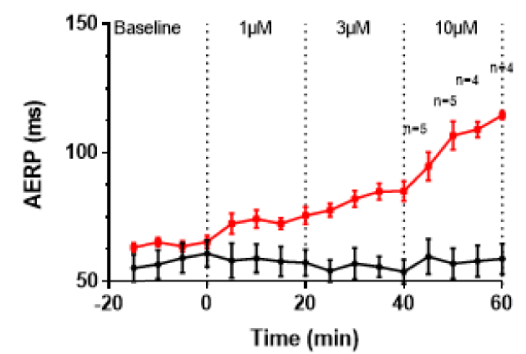

D
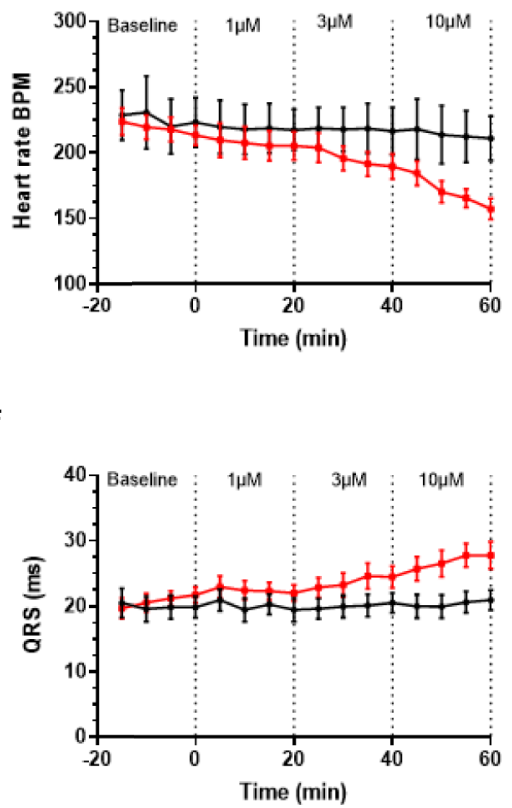

FIGURE 5 | AP30663 prolongs the atrial refractory period in isolated perfused female guinea pig hearts. (A) Monophasic action potential recording recorded from the atrium of an isolated perfused guinea pig heart, during investigation of the atrial effective refractory period (AERP). Ten pacing stimuli (S1) are delivered at fixed basic cycle length of $200 \mathrm{~ms}$, and for every 10th beat, an extra stimulus (S2 marked by * in the recording) is applied with 1 ms increments (for clarity not all S2 are shown). Notice how the first S2 does not result in an atrial action potential, whereas the second S2 (+1 ms) elicits an action potential. Graph demonstrating the effect of increasing concentrations of AP30663 on AERP (B), QTcH-interval (C), heart rate (D), PQ-interval (E), and QRS-duration (F) as compared with time matched control experiments (TMC) (AP30663, $n=6$; TMC, $n=6)$.

$(\sim 8 \mathrm{~ms})$ as compared to the effects of AP30663 on atrial refractoriness (10-50 ms). Similar experiments were conducted in male guinea pigs. No sex differences were observed (see Supplementary Figure 1 and Supplementary Table 1).

\section{AP30663 Prolongs Atrial Refractoriness In Vivo}

To investigate the in vivo effects of AP30663, male rats were infused with increasing doses of AP30663 (5 and $10 \mathrm{mg} / \mathrm{kg}$ ) or corresponding volumes of vehicle ( 1 and $2 \mathrm{ml} / \mathrm{kg}$ ), while intracardiac recordings of AERP were performed. The AERP was significantly prolonged by $5 \mathrm{mg} / \mathrm{kg}$ and $10 \mathrm{mg} / \mathrm{kg}$ of AP30663 to $143 \%$ and $250 \%$ of TMC values (Figure 6).

\section{AP30663 Does Not Impair Coordination in Mice}

$\mathrm{K}_{\mathrm{Ca}} 2$ channels are expressed in the brain including cerebellum, and inhibition of these may lead to motor function impairment (Simó-Vicens et al., 2017). An observational Irwin test for assessing CNS exposure of AP30663 was performed in mice. Neither CNS related adverse effects nor other adverse effects were observed within $30 \mathrm{~min}$ of injection of $10 \mathrm{mg} / \mathrm{kg}$ i.v. AP30663 ( $n=3$, data not shown).

\section{DISCUSSION}

$\mathrm{K}_{\mathrm{Ca}} 2$ channels are widely expressed in the body. In the heart, $\mathrm{K}_{\mathrm{Ca}} 2$ channels are functionally more important for 
TABLE 1 | Effect of AP30663 on isolated perfused female guinea pig hearts.

\begin{tabular}{|c|c|c|c|c|}
\hline AP30663 concentration & & $1 \mu \mathrm{M}$ & $3 \mu \mathrm{M}$ & $10 \mu \mathrm{M}$ \\
\hline \multirow[t]{3}{*}{ AERP (ms) } & TMC & $-4 \pm 1$ & $-7 \pm 1$ & $-2 \pm 2$ \\
\hline & AP30663 & $10 \pm 3$ & $20 \pm 3$ & $47 \pm 4$ \\
\hline & $P$ & 0.002 & $<0.001$ & $<0.001$ \\
\hline \multirow[t]{3}{*}{ QTcH (ms) } & TMC & $0 \pm 1$ & $-2 \pm 2$ & $-3 \pm 3$ \\
\hline & AP30663 & $8 \pm 2$ & $8 \pm 3$ & $7 \pm 5$ \\
\hline & $P$ & 0.029 & 0.053 & 0.099 \\
\hline \multirow[t]{3}{*}{ HR (BPM) } & TMC & $-6 \pm 3$ & $-7 \pm 4$ & $-12 \pm 5$ \\
\hline & AP30663 & $-8 \pm 4$ & $-24 \pm 4$ & $-56 \pm 2$ \\
\hline & $P$ & 0.672 & 0.019 & $<0.001$ \\
\hline \multirow[t]{3}{*}{ QRS (ms) } & TMC & $0 \pm 1$ & $1 \pm 1$ & $1 \pm 1$ \\
\hline & AP30663 & $0 \pm 0$ & $3 \pm 1$ & $6 \pm 1$ \\
\hline & $P$ & 0.392 & 0.203 & 0.007 \\
\hline \multirow[t]{3}{*}{$\mathrm{PQ}$ (ms) } & $\mathrm{TMC}$ & $-1 \pm 1$ & $1 \pm 1$ & $1 \pm 3$ \\
\hline & AP30663 & $4 \pm 2$ & $7 \pm 2$ & $12 \pm 2$ \\
\hline & $P$ & 0.035 & 0.024 & 0.024 \\
\hline
\end{tabular}

Changes in AERP, QTCH, HR, PQ, and QRS ( $\Delta d r u g$, baseline) for each group (TMC and AP30663) calculated at the end of drug period (20,40, and $60 \mathrm{~min})$. $P$ values refer to the comparison of $\Delta$ values between TMC and AP30663 groups.
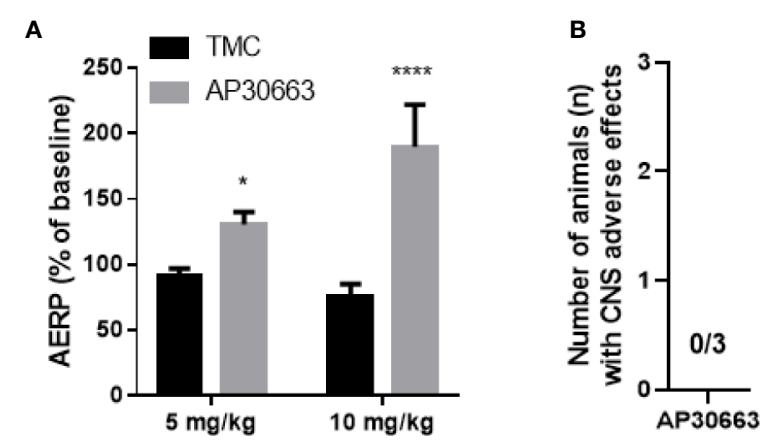

FIGURE 6 | AP30663 prolongs the atrial refractory period in vivo in rats and does not induce CNS related adverse effects in mice. (A) The effect of i.v. injection of AP30663 or vehicle (time matched control, TMC) on AERP evaluated in anaesthetized rats using an intracardiac pacing catheter positioned in the right atria (TMC, $n=4$; AP30663, $n=3$ ). (B) Bar graph depicting the number of mice with CNS related adverse effects triggered by the i.v administration of AP30663 (10 mg/kg), $\mathrm{n}=3 .{ }^{*} 0,0187,{ }^{\star \star \star *}<0,0001$.

repolarization of the atria as compared to the ventricles (Diness et al., 2010; Qi et al., 2014; Skibsbye et al., 2014; Zhang et al., 2014; Haugaard et al., 2015; Diness et al., 2017). Pharmacological experiments on mice, rats, guinea pigs, rabbits, pigs, goats, dogs and horses have demonstrated that $\mathrm{K}_{\mathrm{Ca}} 2$ channel inhibitors can prolong atrial refractoriness, terminate $\mathrm{AF}$ and prevent reinduction of AF (Diness et al., 2010; Diness et al., 2011; Qi et al., 2014; Haugaard et al., 2015; Gatta et al., 2019). In addition, we previously demonstrated that $\mathrm{K}_{\mathrm{Ca}} 2$ channel inhibition can cardiovert vernakalant-resistant $\mathrm{AF}$ in atrially tachypaced pigs (Diness et al.), and prolong atrial but not ventricular APD in human multicellular preparations (Skibsbye et al., 2014). Moreover, genome wide association studies have put the $\mathrm{K}_{\mathrm{Ca}} 2$ channel (KCNN2 and KCNN3) on the list of genes that are highly associated with AF (Ellinor et al., 2010; Ellinor et al., 2012; Christophersen et al., 2017). $\mathrm{K}_{\mathrm{Ca}} 2$ channels thus constitute an interesting novel drug target for treatment of AF.
The advances of genomics and transcriptomics allow us to study possible associations between genetic variants and their influence on mRNA expression levels (eQTL analyses), and hence guide drug discovery. Here we performed eQTL analyses and found that the AFincreasing variant of $\mathrm{rs} 13376333$ is associated with increased mRNA expression of KCNN3 in human atrial tissue. This suggests that increased $\mathrm{K}_{\mathrm{Ca}} 2$ channel mRNA is associated with $\mathrm{AF}$, and hence points towards the possibility of developing $\mathrm{K}_{\mathrm{Ca}} 2$ channel inhibitors for the treatment of AF. To this end, we have developed AP30663. AP30663 is an inhibitor of $\mathrm{K}_{\mathrm{Ca}} 2$ channels with no $\mathrm{K}_{\mathrm{Ca}} 2$-subtype selectivity amongst $\mathrm{K}_{\mathrm{Ca}} 2.2$ and $\mathrm{K}_{\mathrm{Ca}} 2.3$ but a slightly lower potency on $\mathrm{K}_{\mathrm{Ca}} 2.1$, which is the $\mathrm{K}_{\mathrm{Ca}} 2$ subtype found to be least expressed in the human heart (Skibsbye et al., 2014). AP30663 inhibits the $\mathrm{K}_{\mathrm{Ca}} 2$ channels when applied to both the intra- and extracellular side of the plasma membrane. From inside-out recordings we found that AP30663 significantly shifts the $\mathrm{EC}_{50}$ for calcium activation and lowers the Hill-slope, suggesting that AP30663 decreases the calcium sensitivity of $\mathrm{K}_{\mathrm{Ca}} 2$ channels thereby acting as a negative allosteric modulator of the channel. This is similar to what has been reported for two other $\mathrm{K}_{\mathrm{Ca}} 2$ inhibitors, NS8593 and AP14145 (Strøbaek et al., 2006; Simó-Vicens et al., 2017, 14145). Likewise, a changed Hillslope was also observed for NS8593 and AP14145 and may indicate a loss of calcium cooperativity. AP30663 was functionally tested on a broad panel of other cardiac ion channels, and $10 \mu \mathrm{M}$ AP30663 did not significantly affect the $\mathrm{K}_{\mathrm{ir}} 3.1 / \mathrm{K}_{\mathrm{ir}} 3.4\left(\mathrm{I}_{\mathrm{KACh}}\right), \mathrm{K}_{\mathrm{V}} 1.5\left(\mathrm{I}_{\mathrm{Kur}}\right), \mathrm{K}_{\mathrm{V}} 7.1 /$ $\operatorname{KCNE} 1\left(\mathrm{I}_{\mathrm{Ks}}\right), \mathrm{K}_{\mathrm{V}} 4.3 / \mathrm{KChiP} 2\left(\mathrm{I}_{\mathrm{to}}\right), \mathrm{K}_{\mathrm{ir}} 2.1\left(\mathrm{I}_{\mathrm{K} 1}\right)$ and $\mathrm{Ca}_{\mathrm{V}} 2.1\left(\mathrm{I}_{\mathrm{Ca}, \mathrm{L}}\right)$ channels (the latter tested up to $30 \mu \mathrm{M}$ ). A concentration-dependent inhibition of $\mathrm{K}_{\mathrm{V}} 11.1$ by AP30663 was observed, with a calculated $\mathrm{IC}_{50}$ of 15 or $4 \mu \mathrm{M}$ depending on assay type. The difference in potency can likely be explained by the differences in temperature, voltage protocols, and $\mathrm{K}_{\mathrm{V}} 11.1$ isoforms investigated (homomeric $\mathrm{K}_{\mathrm{V}} 11.1 \mathrm{a}$ vs. heteromeric $\mathrm{K}_{\mathrm{V}} 11.1 \mathrm{a} / \mathrm{K}_{\mathrm{V}} 11 . \mathrm{b}$ channels). Minor effects of $10 \mu \mathrm{M}$ AP30663 on peak $\mathrm{I}_{\mathrm{Na}}$, but a significant inhibition of the late $\mathrm{I}_{\mathrm{Na}}$ was observed. Selective inhibition of late $\mathrm{I}_{\mathrm{Na}}$ is known to suppress ventricular arrhythmias, especially in settings of prolonged ventricular repolarization (Antzelevitch et al., 2004; Wu et al., 2004; Undrovinas and Maltsev, 2008; Antoons et al., 2010; Antzelevitch et al., 2011). Late $\mathrm{I}_{\mathrm{Na}}$ has been found in atrial cardiomoycytes from patients with and without AF, although only at room temperature and not at physiological temperatures (Poulet et al., 2015). Ranolazine, which inhibits various ion channels in addition to also inhibiting the late $\mathrm{I}_{\mathrm{Na}}$, has demonstrated anti-AF efficacy in a number of studies (Scirica et al., 2007; Miles et al., 2011). Experimental evidence, however, indicates that ranolazine works against $\mathrm{AF}$ only at concentrations that also inhibit $\mathrm{I}_{\mathrm{Kr}}$ and peak $\mathrm{I}_{\mathrm{Na}}$ in atria (Burashnikov and Antzelevitch, 2013; Du et al., 2014). Late $\mathrm{I}_{\mathrm{Na}}$ is reduced at higher heart rates and would not be expected to play a significant role during tachyarrhythmias such as AF (Burashnikov and Antzelevitch, 2013). Whether or not the inhibition of late $\mathrm{I}_{\mathrm{Na}}$ seen by $10 \mu \mathrm{M}$ AP30663 contributes to any antiarrhythmic activity of the compound is therefore unknown.

AP30663 consistently led to concentration- and dose-dependent prolongation of atrial refractoriness in ex vivo and in vivo experiments. Even though $\mathrm{K}_{\mathrm{Ca}} 2$ channels are expressed in both atria and ventricles in guinea pigs (Kirchhoff et al., 2019), targeting $\mathrm{K}_{\mathrm{Ca}} 2$ channel has previously been shown to be atrial selective in a 
wide range of species, including measurement on human heart tissue (Diness et al., 2010; Qi et al., 2014; Skibsbye et al., 2014; Zhang et al., 2014; Haugaard et al., 2015; Diness et al., 2017). Similarly, in the current study AP30663 was found to predominantly prolong the atrial refractoriness as compared to ventricular repolarization (QTcH). The QTcH prolongation (8 $\mathrm{ms}$ as compared to TMC) appeared to reach a plateau already at $1 \mu \mathrm{M}$. Considering the in vitro $\mathrm{IC}_{50}$ of AP30663 on KCa2 $(\sim 1 \mu \mathrm{M})$ and $\mathrm{Kv} 11.1(4-15 \mu \mathrm{M})$ and the mRNA expression of KCa2 and KV11.1 channels in guinea pig ventricles (Kirchhoff et al., 2019), the QTcH prolongation could be speculated to arise from combined contribution of ventricular $\mathrm{KCa} 2$ and Kv11.1 inhibition. The apparent observed plateau seen for QT prolongation could however also indicate that Kv11.1 inhibition has a minor impact. At this stage the exact contribution to the minor QT prolongation from $\mathrm{KCa} 2$ and Kv11.1 inhibition can only be speculative. We did not see any effects of AP30663 on QRSduration, which correlates well with the lack of effects on peak $\mathrm{Na}_{\mathrm{V}} 1.5$ currents stimulated at $1 \mathrm{~Hz}$. In addition to prolongation of AERP, the isolated guinea pig heart AP30663 also slows heart rate and prolongs the PQ-interval, suggesting effects on nodal tissue. This is in line with findings from mouse demonstrating that ablation of $\mathrm{K}_{\mathrm{Ca}} 2.2$ reduces the firing of the AV node(Zhang et al., 2008) and pharmacological inhibition of $\mathrm{K}_{\mathrm{Ca}} 2$ channels by apamin reduces the spontaneous firing of the sinus node(Torrente et al., 2017). Sex specific differences in the importance of SK channels for cardiac ventricular electrophysiology have been reported (Chen et al., 2018). However, we did not observe any differences in the response to AP30663 in male and female guinea pigs.

In the brain $\mathrm{K}_{\mathrm{Ca}} 2$ channels contribute to neuronal action potential after hyperpolarization, and inhibition of the channel is known to disturb motor output from the cerebellum. Consequently, AP30663 was designed to have limited CNS exposure, and infusion of AP30663 to conscious mice confirmed this.

\section{CONCLUSION}

AP30663 was found to inhibit the $\mathrm{K}_{\mathrm{Ca}} 2$ channel by decreasing the calcium sensitivity of the channel, while being selective over several relevant cardiac ion channels. Ex vivo and in vivo experiments confirmed the ability of the drug to prolong the AERP in a concentration-dependent fashion with minor effects on the QT interval. Based on this profile, AP30663 is an attractive compound for investigating if $\mathrm{K}_{\mathrm{Ca}} 2$ channel inhibition can be used as a novel antiarrhythmic therapy.

\section{LIMITATIONS}

Although the calcium shift in calcium sensitivity was only investigated for $\mathrm{K}_{\mathrm{Ca}} 2.3$ it is likely that the inhibitory mechanism of AP30663 on $\mathrm{K}_{\mathrm{Ca}} 2.1$ and $\mathrm{K}_{\mathrm{Ca}} 2.2$ is similar based on the high sequence homology between the three isoforms. The selectivity of the compound was investigated using overexpression systems and not on native cardiomyocytes. Hence, some of the complexity of native cardiac ion channel complexes, which potentially could impact the selectivity of the compounds, might have been missed. However, the obtained selectivity data on AP30663 combined with our ex vivo and in vivo ECG data supports that AP30663 does not have major impact on other cardiac ion channels. Moreover, for calcium recordings we only performed 3 experiments, which could limit the conclusion. However from our ex vivo and in vivo recordings we did not observe signs of calcium channel inhibition (e.g. PR interval prolongations and blood pressure drop).

\section{DATA AVAILABILITY STATEMENT}

All datasets generated for this study are included in the article/ Supplementary Material.

\section{ETHICS STATEMENT}

The animal experiments were performed under the license from the Danish Ministry of Justice (2018-15-0201-01430 \& 2016-150201-00850) and in accordance with the Danish guidelines for animal experiments according to the European Commission Directive 86/609/EEC.

\section{AUTHOR CONTRIBUTIONS}

SB, RS-V, LF, LA TS, and KM contributed with acquisition, interpretation and analysis of data. US, MG, and NE contributed with conception and design of the study. BB and JD wrote the first draft of the manuscript and interpreted and analysed the data, and contributed with conception and design of the study. All authors contributed to manuscript revision, read and approved the submitted version.

\section{FUNDING}

This work was supported by the Innovation Fund Denmark, Wellcome Trust (grant 100406/Z/12/Z), and the European Union's Horizon 2020 research and innovation programme under the Marie Skłodowska-Curie grant agreement 675351.

\section{ACKNOWLEDGMENTS}

We thank Amer Mujezinovic for expert technical assistance.

\section{SUPPLEMENTARY MATERIAL}

The Supplementary Material for this article can be found online at: https://www.frontiersin.org/articles/10.3389/fphar.2020. 00610/full\#supplementary-material 


\section{REFERENCES}

Antoons, G., Oros, A., Beekman, J. D. M., Engelen, M. A., Houtman, M. J. C., Belardinelli, L., et al. (2010). Late na(+) current inhibition by ranolazine reduces torsades de pointes in the chronic atrioventricular block dog model. J. Am. Coll. Cardiol. 55, 801-809. doi: 10.1016/ j.jacc.2009.10.033

Antzelevitch, C., Belardinelli, L., Wu, L., Fraser, H., Zygmunt, A. C., Burashnikov, A., et al. (2004). Electrophysiologic properties and antiarrhythmic actions of a novel antianginal agent. J. Cardiovasc. Pharmacol. Ther. 9 (Suppl 1), S65-S83. doi: $10.1177 / 107424840400900106$

Antzelevitch, C., Burashnikov, A., Sicouri, S., and Belardinelli, L. (2011). Electrophysiologic basis for the antiarrhythmic actions of ranolazine. Heart Rhythm. 8, 1281-1290. doi: 10.1016/j.hrthm.2011.03.045

Burashnikov, A., and Antzelevitch, C. (2013). Role of late sodium channel current block in the management of atrial fibrillation. Cardiovasc. Drugs Ther. 27, 7989. doi: 10.1007/s10557-012-6421-1

Carithers, L. J., Ardlie, K., Barcus, M., Branton, P. A., Britton, A., Buia, S. A., et al. (2015). A Novel Approach to High-Quality Postmortem Tissue Procurement: The GTEx Project. Biopreserv. Biobank. 13, 311-319. doi: 10.1089/bio.2015.0032

Chen, M., Yin, D., Guo, S., Xu, D.-Z., Wang, Z., Chen, Z., et al. (2018). Sex-specific activation of SK current by isoproterenol facilitates action potential triangulation and arrhythmogenesis in rabbit ventricles. J. Physiol. 596, 4299-4322. doi: 10.1113/JP275681

Christophersen, I. E., Rienstra, M., Roselli, C., Yin, X., Geelhoed, B., Barnard, J., et al. (2017). Large-scale analyses of common and rare variants identify 12 new loci associated with atrial fibrillation. Nat. Genet. 49, 946-952. doi: $10.1038 /$ ng. 3843

Diness, J. G., Sørensen, U. S., Nissen, J. D., Al-Shahib, B., Jespersen, T., Grunnet, M., et al. (2010). Inhibition of small-conductance Ca2+-activated K+ channels terminates and protects against atrial fibrillation. Circ. Arrhythm. Electrophysiol. 3, 380-390. doi: 10.1161/CIRCEP.110.957407

Diness, J. G., Skibsbye, L., Jespersen, T., Bartels, E. D., Sørensen, U. S., Hansen, R. S., et al. (2011). Effects on atrial fibrillation in aged hypertensive rats by $\mathrm{Ca}(2$ +)-activated $\mathrm{K}(+)$ channel inhibition. Hypertension 57, 1129-1135. doi: 10.1161/ HYPERTENSIONAHA.111.170613

Diness, J. G., Skibsbye, L., Simó-Vicens, R., dos Santos, J., Lundegaard, P. R., Citerni, C., et al. (2017). Termination of Vernakalant-Resistant Atrial Fibrillation by Inhibition of Small Conductance Ca2+-Activated $\mathrm{K}+$ Channels in pigs. Circ. Arrhythm. Electrophysiol. 10 (10). doi: 10.1161/ CIRCEP.117.005125

Du, C., Zhang, Y., El Harchi, A., Dempsey, C. E., and Hancox, J. C. (2014). Ranolazine inhibition of hERG potassium channels: drug-pore interactions and reduced potency against inactivation mutants. J. Mol. Cell. Cardiol. 74, 220-230. doi: 10.1016/j.yjmcc.2014.05.013

Ellinor, P. T., Lunetta, K. L., Glazer, N. L., Pfeufer, A., Alonso, A., Chung, M. K., et al. (2010). Common variants in KCNN3 are associated with lone atrial fibrillation. Nat. Genet. 42, 240-244. doi: 10.1038/ng.537

Ellinor, P. T., Lunetta, K. L., Albert, C. M., Glazer, N. L., Ritchie, M. D., Smith, A. V., et al. (2012). Meta-analysis identifies six new susceptibility loci for atrial fibrillation. Nat. Genet. 44, 670-675. doi: 10.1038/ng.2261

Folkersen, L., Wågsäter, D., Paloschi, V., Jackson, V., Petrini, J., Kurtovic, S., et al. (2011). Unraveling divergent gene expression profiles in bicuspid and tricuspid aortic valve patients with thoracic aortic dilatation: the ASAP study. Mol. Med. 17, 1365-1373. doi: 10.2119/molmed.2011.00286

Gatta, G., Sobota, V., SØRENSEN, U. S., DINESS, J. G., Verheule, S., Schotten, U., et al. (2019). Unraveling the Antiarrhythmic Action of SK Channel Block in a Goat Model of Stable Atrial Fibrillation. Heart Rhythm. (HRS 2019) 2019.

Haugaard, M. M., Hesselkilde, E. Z., Pehrson, S., Carstensen, H., Flethøj, M., Præstegaard, K. F., et al. (2015). Pharmacologic inhibition of smallconductance calcium-activated potassium (SK) channels by NS8593 reveals atrial antiarrhythmic potential in horses. Heart Rhythm. 12, 825-835. doi: 10.1016/j.hrthm.2014.12.028

Heijman, J., and Dobrev, D. (2017). Inhibition of Small-Conductance Ca2+-Activated K+ Channels: The Long-Awaited Breakthrough for Antiarrhythmic Drug Therapy of Atrial Fibrillation? Circ. Arrhythm. Electrophysiol. 10 (10). doi: 10.1161/ CIRCEP.117.005776
Holzgrefe, H., Ferber, G., Champeroux, P., Gill, M., Honda, M., Greiter-Wilke, A., et al. (2014). Preclinical QT safety assessment: Cross-species comparisons and human translation from an industry consortium. J. Pharmacol. Toxicol. Methods 69, 61-101. doi: 10.1016/j.vascn.2013.05.004

Isenberg, G., and Ravens, U. (1984). The effects of the Anemonia sulcata toxin (ATX II) on membrane currents of isolated mammalian myocytes. J. Physiol. 357, 127-149. doi: 10.1113/jphysiol.1984.sp015493

Kirchhof, P., Benussi, S., Kotecha, D., Ahlsson, A., Atar, D., Casadei, B., et al. (2016). 2016 ESC Guidelines for the management of atrial fibrillation developed in collaboration with EACTS. Eur. Heart J. 37, 2893-2962. doi: 10.1093/eurheartj/ehw210

Kirchhoff, J. E., Skarsfeldt, M. A., Muthukumarasamy, K. M., Simó-Vicens, R., Bomholtz, S. H., Abildgaard, L., et al. (2019). The KCa2 Channel Inhibitor AP14145, But Not Dofetilide or Ondansetron, Provides Functional Atrial Selectivity in Guinea Pig Hearts. Front. Pharmacol. 10, 668. doi: 10.3389/fphar.2019.00668

Li, N., Timofeyev, V., Tuteja, D., Xu, D., Lu, L., Zhang, Q., et al. (2009). Ablation of a Ca2+-activated $\mathrm{K}+$ channel (SK2 channel) results in action potential prolongation in atrial myocytes and atrial fibrillation. J. Physiol. (Lond.) 587, 1087-1100. doi: 10.1113/jphysiol.2008.167718

Maltsev, V. A., Sabbah Hani, N., Higgins Robert, S. D., Silverman, N., Lesch, M., and Undrovinas, A. I. (1998). Novel, Ultraslow Inactivating Sodium Current in Human Ventricular Cardiomyocytes. Circulation 98, 2545-2552. doi: 10.1161/ 01.CIR.98.23.2545

Miles, R. H., Passman, R., and Murdock, D. K. (2011). Comparison of effectiveness and safety of ranolazine versus amiodarone for preventing atrial fibrillation after coronary artery bypass grafting. Am. J. Cardiol. 108, 673-676. doi: 10.1016/j.amjcard.2011.04.017

Poulet, C., Wettwer, E., Grunnet, M., Jespersen, T., Fabritz, L., Matschke, K., et al. (2015). Late Sodium Current in Human Atrial Cardiomyocytes from Patients in Sinus Rhythm and Atrial Fibrillation. PloS One 10, e0131432. doi: 10.1371/ journal.pone.0131432

Qi, X.-Y., Diness, J. G., Brundel, B. J. J. M., Zhou, X.-B., Naud, P., Wu, C.-T., et al. (2014). Role of small-conductance calcium-activated potassium channels in atrial electrophysiology and fibrillation in the dog. Circulation 129, 430-440. doi: 10.1161/CIRCULATIONAHA.113.003019

Scirica, B. M., Morrow, D. A., Hod, H., Murphy, S. A., Belardinelli, L., Hedgepeth, C. M., et al. (2007). Effect of ranolazine, an antianginal agent with novel electrophysiological properties, on the incidence of arrhythmias in patients with non ST-segment elevation acute coronary syndrome: results from the Metabolic Efficiency With Ranolazine for Less Ischemia in Non ST-Elevation Acute Coronary Syndrome Thrombolysis in Myocardial Infarction 36 (MERLIN-TIMI 36) randomized controlled trial. Circulation 116, 1647-1652. doi: 10.1161/CIRCULATIONAHA. 107.724880

Simó-Vicens, R., Kirchhoff, J. E., Dolce, B., Jensen, L. A., Speerschneider, T., Sørensen, U. S., et al. (2017). A New Negative Allosteric Modulator AP14145 for the Study of Small Conductance Calcium-Activated Potassium Channels. Br. J. Pharmacol. 174 (23), 4396-4408. doi: 10.1111/ bph. 14043

Skibsbye, L., Poulet, C., Diness, J. G., Bentzen, B. H., Yuan, L., Kappert, U., et al. (2014). Small-conductance calcium-activated potassium (SK) channels contribute to action potential repolarization in human atria. Cardiovasc. Res. 103, 156-167. doi: 10.1093/cvr/cvu121

Strøbaek, D., Hougaard, C., Johansen, T. H., Sørensen, U. S., Nielsen, E.Ø., Nielsen, K. S., et al. (2006). Inhibitory gating modulation of small conductance $\mathrm{Ca} 2+$-activated $\mathrm{K}+$ channels by the synthetic compound (R)-N(benzimidazol-2-yl)-1,2,3,4-tetrahydro-1-naphtylamine (NS8593) reduces afterhyperpolarizing current in hippocampal CA1 neurons. Mol. Pharmacol. 70, 1771-1782. doi: 10.1124/mol.106.027110

Torrente, A. G., Zhang, R., Wang, H., Zaini, A., Kim, B., Yue, X., et al. (2017). Contribution of small conductance $\mathrm{K}+$ channels to sinoatrial node pacemaker activity: insights from atrial-specific $\mathrm{Na}+/ \mathrm{Ca} 2+$ exchange knockout mice. $J$. Physiol. 595, 3847-3865. doi: 10.1113/JP274249

Tuteja, D., Xu, D., Timofeyev, V., Lu, L., Sharma, D., Zhang, Z., et al. (2005). Differential expression of small-conductance Ca2+-activated K+ channels SK1, SK2, and SK3 in mouse atrial and ventricular myocytes. Am. J. Physiol. Heart Circ. Physiol. 289, H2714-H2723. doi: 10.1152/ajpheart.00534.2005 
Undrovinas, A., and Maltsev, V. A. (2008). Late sodium current is a new therapeutic target to improve contractility and rhythm in failing heart. Cardiovasc. Hematol. Agents Med. Chem. 6, 348-359. doi: 10.2174/187152508785909447

Waks, J. W., and Zimetbaum, P. (2016). Antiarrhythmic Drug Therapy for Rhythm Control in Atrial Fibrillation. J. Cardiovasc. Pharmacol. Ther. 22 (1), 3-19. doi: 10.1177/1074248416651722

Wu, L., Shryock, J. C., Song, Y., Li, Y., Antzelevitch, C., and Belardinelli, L. (2004). Antiarrhythmic effects of ranolazine in a guinea pig in vitro model of long-QT syndrome. J. Pharmacol. Exp. Ther. 310, 599-605. doi: 10.1124/jpet.104.066100

Zhang, Q., Timofeyev, V., Lu, L., Li, N., Singapuri, A., Long, M. K., et al. (2008). Functional Roles of a Ca2+-Activated K+ Channel in Atrioventricular Nodes. Circ. Res. 102, 465-471. doi: 10.1161/CIRCRESAHA.107.161778

Zhang, X.-D., Timofeyev, V., Li, N., Myers, R. E., Zhang, D.-M., Singapuri, A., et al. (2014). Critical roles of a small conductance Ca2+-activated $\mathrm{K}+$ channel (SK3) in the repolarization process of atrial myocytes. Cardiovasc. Res. 101, 317-325. doi: $10.1093 / \mathrm{cvr} / \mathrm{cvt} 262$
Conflict of Interest: BB, RS-V, TS, NE, US, LA, SB, MG, and GD are employed by and/or have interests in Acesion Pharma and/or are inventors of Acesion Pharma patents within the field of SK channels.

The remaining authors declare that the research was conducted in the absence of any commercial or financial relationships that could be construed as a potential conflict of interest.

Copyright (C) 2020 Bentzen, Bomholtz, Simó-Vicens, Folkersen, Abildgaard, Speerschneider, Muthukumarasamy, Edvardsson, Sørensen, Grunnet and Diness. This is an open-access article distributed under the terms of the Creative Commons Attribution License (CC BY). The use, distribution or reproduction in other forums is permitted, provided the original author(s) and the copyright owner(s) are credited and that the original publication in this journal is cited, in accordance with accepted academic practice. No use, distribution or reproduction is permitted which does not comply with these terms. 